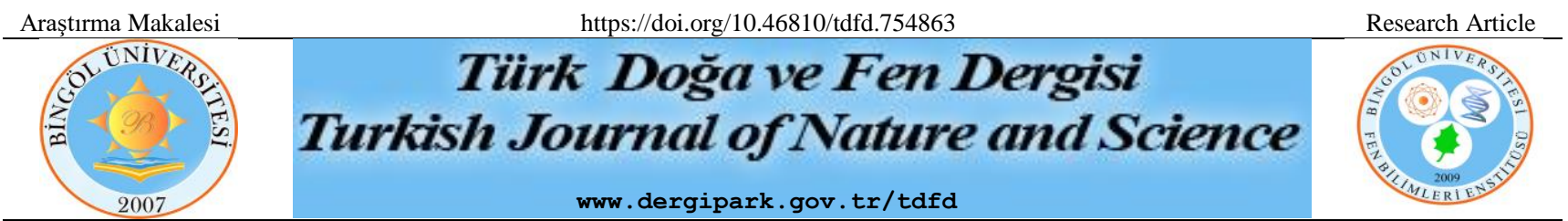

\title{
3B Yazıcı Teknolojisi İçin Topoloji Optimizasyonu: N95 Maske Üzerine Bir Çalışma
}

\author{
Koray ÖZSOY ${ }^{*}$, Emre ŞENTÜRK ${ }^{2}$, Duygu AYDOĞAN ${ }^{2}$, Ömer Emre KORUCU ${ }^{2}$ \\ ${ }^{1}$ Isparta Uygulamalı Bilimler Üniversitesi, Senirkent Meslek Yüksekokulu, Elektrik ve Enerji Bölümü, Isparta, Türkiye \\ ${ }^{2}$ Isparta Uygulamalı Bilimler Üniversitesi, Teknoloji Fakültesi, Mekatronik Mühendisliği Bölümü, Isparta, Türkiye \\ Koray ÖZSOY ORCID No: 0000-0001-8663-4466 \\ Emre ŞENTÜRK ORCID No: 0000-0003-0574-1425 \\ Duygu AYDOĞAN ORCID No: 0000-0002-1847-9633 \\ Ömer Emre KORUCU ORCID No: 0000-0001-7598-5674
}

*Sorumlu yazar: korayozsoy@isparta.edu.tr

(Alınış: 18.06.2020, Kabul: 07.10.2020, Online Yayınlanma: 23.10.2020)

Anahtar
Kelimeler
N95 Maske,
Covid-19,
3B Bask1,
Topoloji
Optimizasyonu

Anahtar

Covid-19,

Topoloji

Optimizasyonu

\begin{abstract}
Öz: Hastalık, bireylerin yaşamı açısından programlanmayan iradesi dışında ve istenmeyen bir durumdur. Hastalık, biyolojik ve psikolojik olarak öncelikle bireyi etkiler. Görünürde tek kişiyi etkilemiş gibi görünse de birden fazla kişiyi etkileyebilir ve bu yüzden zincerleme bir şekilde topluma zarar verebilir. Bulaşıcı hastalıkların tedavisi çok çeşitli olup, hastalık yapıcı mikrobun cinsine göre değişir. Bunlar; grip, kızamık, kolera, menenjit, psittakoz, sıtma, suçiçeği, tetanos, tularemi, tüberküloz, uyku hastalığı, zatürre, tifo, tifüs ve yeni tip koronavirüs (COVID-19) gibi bulaşıcı hastalıklar örnek verilebilir. Yeni koronavirüs hastalı̆ğ (COVID-19), ilk olarak Çin'in Vuhan Eyaleti'nde aralık ayının sonlarında solunum yolu belirtileri (ateş, öksürük, nefes darlığı) gelişen bir grup hastada yapılan araştırmalar sonucunda ilk başta 31 Aralık 2019 da ortaya çıkan virüs 13 Ocak 2020 'de tanımlanmıştır. Çalışma N95 maske tasarımı üzerinde yapılan topoloji optimizasyonunu kapsamaktadır. Maske filtresinin kolay değiştirilebilmesi için kapak tasarımı buna uygun ergonomide tasarlanmıştır. N95 maske tasarımında; tam dolu katı model ile \%30, $\% 40$ ve $\% 50$ oranında topoloji optimizasyonu ile hafifletme işlemi uygulanmış çizimler yapılmışıı. Elde edilen katı modeller 3B baskı cihazı ile $50 \mathrm{~mm} / \mathrm{sn}$ baskı hızında, $0,2 \mathrm{~mm}$ katman kalınlığında, \%15 doluluk oranında işleme parametreleri ile imal edilmiştir. Tasarımlar, Solidworks® simülasyon programı ile topoloji optimizasyon modülü kullanarak sonlu elemanlar analizi yapılmıştır. Elde edilen bulgular kendi içerisinde karşılaştırma ile değerlendirme yapılmıştır.
\end{abstract}

\section{Topology Optimization For 3D Printer Technology: A Study On The N95 Mask}

Keywords
N95 Mask,
Covid-19,
3D Printer,
Topology
Optimization

\begin{abstract}
The disease is an undesirable and involuntary condition that cannot be programmed for the lives of individuals. The disease primarily affects the individual biologically and psychologically. Even though it may appear to affect only one person, it can affect more than one person and thus harm society in a chain. The treatment of infectious diseases is a great variety and varies according to the type of disease-causing microbe. As an example of the infectious diseases; flu, measles, cholera, meningitis, psittacosis, malaria, chickenpox, tetanus, tularemia, tuberculosis, sleep disease, pneumonia, typhoid, typhus and new types of coronavirus (COVID-19). New coronavirus disease (COVID-19), the virus that first appeared on December 31, 2019, as a result of research in a group of patients who developed respiratory tract symptoms (fever, cough, shortness of breath) in Wuhan Province in late December, January 13. It was defined in 2020. The study aims to topology optimization on N95 mask design. The cover design is ergonomically designed for easy replacement of the mask filter. In the N95 mask design, drawings with 30\%, $40 \%$, and 50\% topology optimization and lightning are applied with the solid model. The solid models obtained were produced with a 3D printing device at $50 \mathrm{~mm} / \mathrm{sec}$ printing speed, $0.2 \mathrm{~mm}$ layer thickness, and $15 \%$ fullness processing parameters. The designs were analyzed by using Solidworks ${ }^{\circledR}$ simulation program and topology optimization module. The obtained findings were evaluated by comparison within themselves.
\end{abstract}




\section{GİRIŞ}

Hastalık, bireylerin yaşamı açısından iradesi dışında ve istenmeyen bir durumdur. Hastalık durumunun niteliği, süresi, yoğunluk derecesi hastalık tiplerine göre farklılıklar gösterir. Hastalık, biyolojik ve psikolojik olarak öncelikle bireyi etkiler. Görünürde tek kişiyi etkilemiş gibi görünse de birden fazla kişiyi etkileyebilir ve bu yüzden zincirleme bir şekilde topluma zarar verebilir. Hastalıkların tanımlanma sürecinde hem bireyin kendisi hem de çevresindekilerle birlikte değerlendirilmeleri çok büyük önem taşımaktadır [1]. Bulaşıcı hastalıkların tedavisi çok çeşitli olup, hastalık yapıcı mikrobun cinsine göre değişir. Virüs hastalıkları ise antibiyotiklerden etkilenmezler. Belli başlı bulaşıcı hastalıklar: belsoğukluğu, bruselloz, çiçek hastalığı, difteri, dizanteri (amipli veya basilli), grip, hepatit, kızamık, kolera, menenjit, psittakoz, sıtma, suçiçeği, tetanos, tularemi, tüberküloz, uyku hastalığı, zatürre, tifo, tifüs ve yeni tip koronavirüs (COVID-19)'dur [2].

Şekil 1'de gösterildiği gibi yeni koronavirüs hastalığ 1 (COVID-19), ilk olarak Çin'in Vuhan Eyaleti'nde aralık ayının sonlarında solunum yolu belirtileri (ateş, öksürük, nefes darlığı) gelişen bir grup hastada yapılan araştırmalar sonucunda ilk başta 31 Aralık 2019'da ortaya çıkan virüs 13 Ocak 2020'de tanımlanmıştır. Koronavirüsler, hayvanlarda veya insanlarda hastalığa neden olabilecek büyük bir virüs ailesidir. İnsanlarda, birkaç koronavirüsün soğuk algınlığından Orta Doğu Solunum Sendromu (MERS) ve Şiddetli Akut Solunum Sendromu (SARS) gibi daha şiddetli hastalıklara kadar solunum yolu enfeksiyonlarına neden olduğu bilinmektedir. Yeni Koronavirüs Hastalığına SAR-CoV2 virüsü neden olur [3].

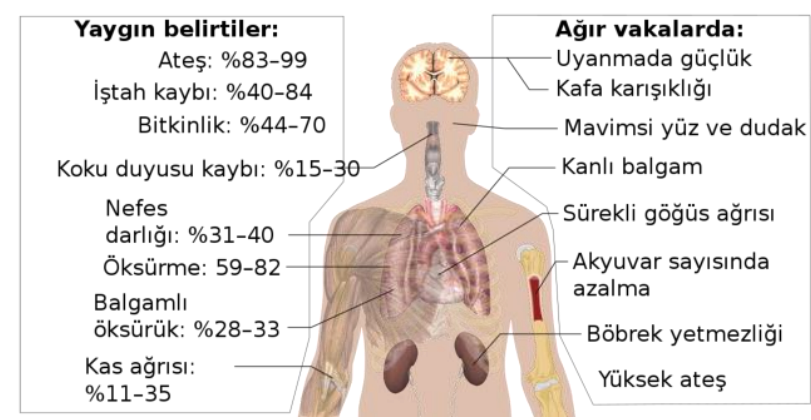

Şekil 1. Covid-19 belirtileri [4]

Sağlık çalışanlarının hastalar ile daha yakın temas halinde bulunmaları sonucu daha iyi ve güvenilir bir şekilde virüsten korunmaları gerekmektedir [5]. COVID19 salgını ile mücadelede 3D baskı uygulamaları, kişisel koruyucu ekipman (KKE), tıbbi ve test cihazları parçaları, kişisel aksesuarlar, kişiye özel görselleştirme yardımcı parçaları ve acil durum konutları gibi geniş bir yelpaze içerisinde kullanımı vardır [6,7]. Son zamanlardaki koronavirüs pandemisi, tüm dünyadaki sağlık çalışanlarının hasta ve güvenliğinin sağlanmasında zorluklar yaratan kişisel koruyucu ekipman (KKE) sıkıntısı yaratmıştır. Sağlık çalışanlarının maskelerinin de kısa bir zaman içinde tüketilmesi ile tedarik etmek de oldukça sıkıntılı hale gelmektedir, üretimin hızlandırılması amaciyla 3B yazıcılardan faydalanılarak koruyucu siperlerin plastik kısımları üretilmektedir [8]. Koruyucu siperliklerin iki plastik parçası bulunmaktadır. 3B yazıcı ile üretilen bölüme steril edilebilir asetat kâğıt takılır daha sonra ikinci parça da koruyucu siperin alt kısmına takılarak yüzün şeklini alması ve virüsten olabildiğinde korunması amaçlanmaktadır [9]. 3B baskı teknolojileri çalışma prensibi, eklemeli imalat (additive manufacturing) olarak nitelendirilen bir üretim yöntemini benimsemektedir.

3B baskı teknolojileri çalışma prensibi, eklemeli imalat (ing. additive manufacturing) olarak nitelendirilen bir üretim yöntemini benimsemektedir. Sanal ortamda tasarlanan 3B modellerin katı nesnelere dönüştüren makineler 3B yazıcı denir. 3B yazıcı ile istenilen her türlü parça, model ve aksesuarın basılması mümkündür. 3B yazıcılar, eklemeli imalat yöntemi olarak adlandırılan üretim tekniği ile çalışmaktadır. Baskı için başta termoplastik hammaddeler kullanılmaktadır ve bunlara filament ismi verilir. 3B yazıcıların bir 3B modele ihtiyacı vardır. Bunun için bilgisayar destekli tasarım programlarına ihtiyaç duyulmaktadır. Tasarlanmış modeller veya 3B taranan cisimler. STL uzantısı ile 3B yazıcıya aktarılır. 3B yazıcılar, STL formatındaki dosyalar ile çalışmaktadır. 3B baskı filamentin yarı eriyik halde katmanlar oluşturacak şekilde tablaya dizilmesi ile imalat yapılır [10].

3B yazıcıların çalışabilmesi için 3B bir modele ihtiyaç duyulmaktadır. Bilgisayar ortamında AutoCAD, SolidWorks, 3DS, gibi bir CAD (Bilgisayar Destekli Tasarım) programı ile tasarlanmalıdır veya $3 \mathrm{~B}$ tarayıcılar ile taranmış nesneler '.stl' formatı ile 3B yazıcıya aktarılmalıdırlar. Literatürde yapılan çalışmalar incelendiğinde 3B baskı teknolojisi ile '.stl' uzantılı dosyayı algılar baskıyı gerçekleştirmektedir [11-13].

COVID-19 salgınına karşı önleyici ve koruyucu tedbirler kapsamında acil ihtiyaç duyulan ürünler 3B yazıcı teknolojisi ile imalatı gerçekleştirilmektedir. Bunların en önemlisi insanların ihtiyaçlarını karşılayabilmek amaciyla koruyucu maske tasarımı veya maske kalıbı, koruyucu siper, filtre sabitleme, mühür vb. gibi maske bileşenlerini içeren ürünler, solunum cihazı parçaları ve vantilatör gibi elemanlar 3B yazıcılar ile üretilebilmektedir. Materyal olarak polymax PLA filament, FDM ABS, SLS / MJF naylon veya esnek SLA reçinesi gibi çeşitli farklı malzeme türleri kullanılmıştır. Filamentler kullanım alanı, basım sıcaklığı gibi ayırıcı unsurların etkisiyle birçok çeşitte bulunabilir. Bu çeşitlere PLA, ABS, PETG, Nylon, TPE, TPU, PET gibi filamentler örnek olarak gösterilebilir. Polilaktik asit veya diğer adıyla PLA filament, günümüzde en çok kullanılan filamentlerin başında gelmektedir. PLA filamentin popüler olmasındaki diğer noktalar ise kolay kullanımı, çok yönlü bir kullanım alanın bulunmasıdır. PLA filamentin tercih sebeplerinden bir diğeri de mekanik özelliklerinin yeterince iyi olmasıdır plastik, polipropilen ve poliüretan gibi geleneksel kullanımda olan plastik malzemelere göre mekanik özellikleri çok daha iyidir. 3B yazdırılabilir elastomerik polimerlerin veya kalıplanmış silikon bileşenlerin kullanımı cilt ara yüzünde tahrişi azaltmak ve uygun bir sızdırmazlık 
sağlamak için kullanılabilir. Daha iyi hava sızdırmazlığı ve daha yumuşak cilt dokunuşu elde etmek için 3B baskı teknolojisinin malzemesi köpük veya silikon bant kullanılmaktadır [13,14].

3B baskılı ile üretilen maskeler geleneksel KKE'lere benzeyebilir. Ancak aynı seviyede bariyer koruması, sıv1 direnci, filtrasyon ve enfeksiyon kontrolü sağlayamayabilirler. 3B baskı teknoloji ile koruyucu ekipmanların yenilikçi tasarımları herhangi bir düzenleyici kurum tarafından onaylanmamıștır ve performanstan ödün verilmiş olabilir. Ancak düşük maliyetli, hızlı ve merkezi olmayan ve dağıtılmış üretim sağladıkları için, 3B baskılı maskeler acil durumlarda yardımcı olarak görülür $[15,16]$. Örneğin; Ford, $3 \mathrm{M}$ ve General Motors'un birlikte COVID-19 hastalığı olan koronavirüse karş1 koruyucu yüz maskesi teknik özelliklerini içinde barındıran 3B baskılı yüz kalkanları üretmektedir [17]. 3B yazıcıların sağlık sektöründe kullanılma amaçlarından biri kişiye özel koruma ekipmanları üretmektir. Ventilsiz solunum maskesi N95 ya da FFPII, FFPIII gibi adlarla da anılan, çevredeki küçük partiküllerin, bakteri veya virüslerin en az \%95'ini tutan maskelerdir. $\mathrm{Bu}$ maskeler esas olarak sağlık çalışanları tarafından özel durumlarda kullanılmak için üretilmektedir. N95 filtresi, 0.1 mikrona kadar yüksek verimlilikte filtreme yapabilir. N95 maske yapılırken bu maskenin çocuk ve yetişkinler tarafinda kullanılacağı bilindiğinden maske ölçüleri, tasarımı ve malzeme seçimi buna göre yapılmalıdır. Maskenin tasarım aşamasında ergonomik açısından istenilen şartlara uyması istenmektedir. Uzun kullanımlar göze alınarak maskenin ağız çevresi ve yüzde oluşabilecek tahriş ve kesiklere karşı tasarımının yapılması gerekmektedir [18].

Çalışmada, topoloji optimizasyonu ile oluşturulan detayl tasarımların 3B yazıcılarda yazdırılması ile gereken malzeme miktarlarının azaltılması için geliştirilen yenilikçi bir yöntemdir. Çalışma, N95 maske tasarımı üzerinde yapilan topoloji optimizasyonunu kapsamaktadır. Maske filtresinin kolay değiştirilebilmesi için kapak tasarımı buna uygun ergonomide tasarlanmıştır. N95 maske tasarımında; tam dolu katı model ile \%30, \%40 ve \%50 oranında topoloji optimizasyonu ile hafifletme işlemi uygulanmış çizimler yapılmıștır. Elde edilen katı modeller 3B baskı cihazı ile $50 \mathrm{~mm} / \mathrm{sn}$ baskı hızında, 0,2 mm katman kalınlığında, $\% 15$ doluluk oranında işleme parametreleri ile imal edilmiștir. Tasarımlar, Solidworks ${ }^{\circledR}$ simülasyon programı ile topoloji optimizasyon modülü kullanarak sonlu elemanlar analizi yapılmıştır. Elde edilen bulgular kendi içerisinde karşılaştırma ile değerlendirme yapılmıştır.

\section{MATERYAL VE METOT}

\subsection{Materyal}

Çalışmada, Şekil 2'de 3B yazıcı olarak gösterildiği gibi Creality3D Ender-3 Pro modeli kullanılmıştır. Tüm teknik özellikler ve sabit parametreler Tablo 1'de gösterilmiştir.

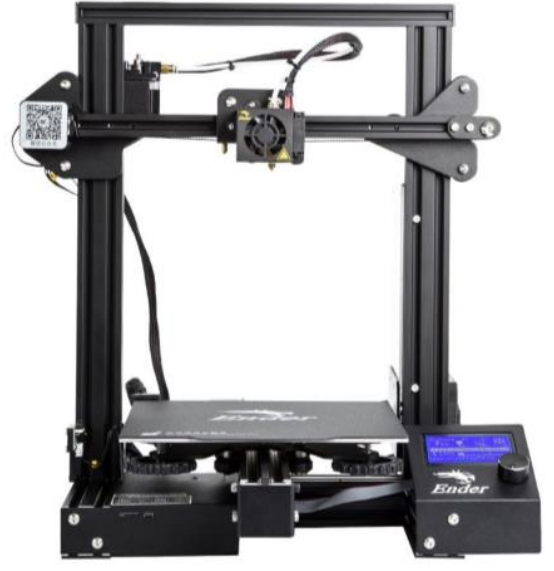

Şekil 2. Creality3D Ender-3 Pro yazıcının görüntüsü

\begin{tabular}{|c|c|}
\hline Model & Ender- 3 Pro \\
\hline Bask1 Boyutu & $220 * 220 * 250 \mathrm{~mm}$ \\
\hline Baskı Hızı ve hassasiyeti & $180 \mathrm{~mm} / \mathrm{s}, \pm 0.1 \mathrm{~mm}$ \\
\hline Katman Kalınlığ & $0.1-0.4 \mathrm{~mm}$ \\
\hline Nozzle Boyutu & $\begin{array}{l}\text { Standart } 0.4 \mathrm{~mm}(0.2,0.3 \mathrm{~mm} \text { Nozzle } \\
\text { kullanılabilir.) Maksimum Sicaklığı, } \\
225^{\circ} \mathrm{C}\end{array}$ \\
\hline Tabla Sicaklığı & $\leq 110^{\circ} \mathrm{C}$ \\
\hline $\begin{array}{l}\text { Desteklenen Dosya } \\
\text { Format1 }\end{array}$ & .stl, .obj, .amf \\
\hline $\begin{array}{ll}\text { Desteklenen } & \text { Bask1 } \\
\text { Programları } & \end{array}$ & Cura, Repetier-Host, Simplify3D \\
\hline Filament & $\begin{array}{l}1.75 \mathrm{~mm} \text { PLA, ABS, Flexible, Karbon } \\
\text { Fiber vb. }\end{array}$ \\
\hline Ağırlık & $6.9 \mathrm{~kg}$ \\
\hline Makine Boyutu & $440 * 440 * 465 \mathrm{~mm}$ \\
\hline
\end{tabular}

Tablo 2'de çalışmada kullanılacak PLA filamenti hakkında teknik bilgi ve parametreler verilmiştir. Çalışmada, $1.75 \mathrm{~mm}$ çapında PLA filamenti tercih edilmiştir.

Tablo 2. PLA filamentin teknik özellikleri

\begin{tabular}{|c|c|}
\hline Filament & PLA \\
\hline Gerilme Direnci & $65 \mathrm{MPa}$ \\
\hline Maksimum Çalışma Sıcaklığ1 & $52^{\circ} \mathrm{C}$ \\
\hline Termal Genleşme Katsayısı & $68 \mu \mathrm{m} / \mathrm{m}-{ }^{\circ} \mathrm{C}$ \\
\hline Yoğunluk & $1.24 \mathrm{~g} / \mathrm{cm}^{3}$ \\
\hline Ekstrüzyon Sicaklığ1 & $190-220^{\circ} \mathrm{C}$ \\
\hline Tabla Sıcaklığ1 & $45-60^{\circ} \mathrm{C}$ \\
\hline
\end{tabular}

\subsection{Metot}

\subsubsection{N95 maske tasarımı}

Çalışmada literatür taramasında edinilen bilgiler 1şı̆̆ında N95 maskenin insan anatomisine uygunluğu tasarımın en önemli evrelerinden birini oluşturmaktadır. Maske filtresinin kolay değiştirilebilmesi için kapak tasarımı buna uygun ergonomide tasarlanmıştır. Tasarım yapılırken gündelik kullanılan filtresiz maskelerin tasarımlarında olan eksi ve artı özelliklere dikkat edilerek gerekli iyileştirmeler yapılmıştır. Şekil 3'de Solidworks ${ }^{\circledR}$ [19] ile çizilmiş N95 maske tasarımı gösterilmiştir. 

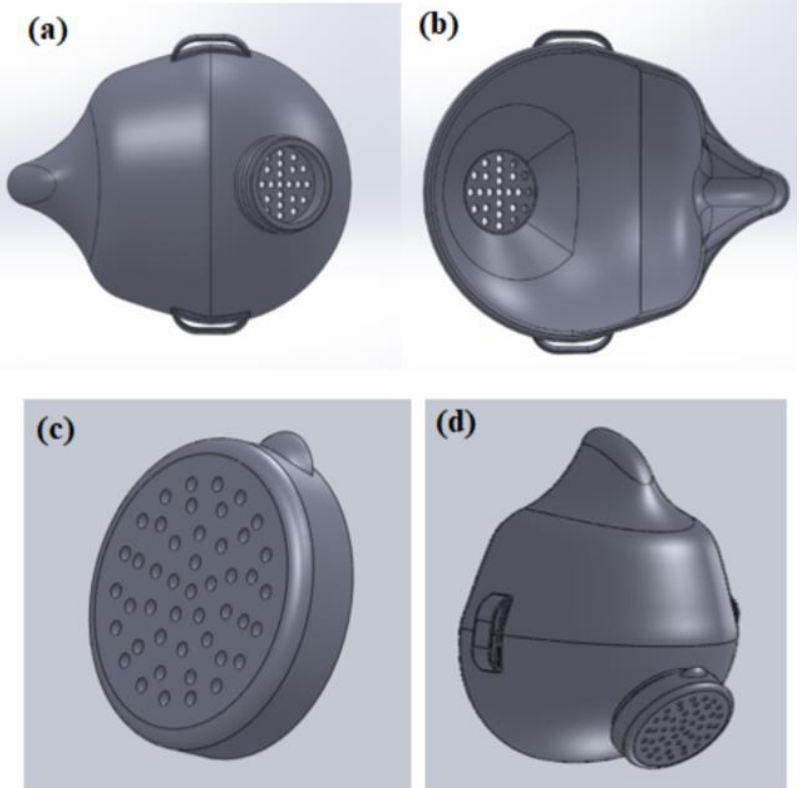

Şekil 3. N95 maskenin görüntüsü a) ön görünüşü b) iç yüzey görünüși c) kapak görüntüsü d) N95 maske montajlanmış görüntüsü

\subsubsection{Topoloji optimizasyonu}

Topoloji optimizasyonu, bir tasarım içerisindeki malzeme dağılımını belirli yük ve sınır koşullarına bağlı olarak en iyi şekilde optimize eden istenilen tasarım ve üretime ulaşılmasını sağlayan bir tasarım tekniğidir. Çalışmada, Şekil 4'de gösterildiği gibi hem malzemeden hem de zamandan tasarruf sağlanarak maliyeti daha düşük ve hızlı bir çözüm bulmak için Solidworks ${ }^{\circledR}$ Simulation programı ile topoloji optimizasyonu çalışması yapılmıştır. Malzeme olarak PLA hammaddesi seçilmiştir. İki kenardan sabitlemeleri yapıldıktan sonra, yük bindirmek için 600 mbar N95 maskenin ön yüzeyine basınç uygulanmıştır. Çalışmada "En iyi Sertlik ve Ağırlık oranı" seçeneği seçilmiş olup azaltılacak kütle yüzde parametresi simülasyona girilmiştir. Mesh işlemi yapıldıktan sonra topoloji optimizasyonu için gereken ön işlemler tamamlanmıştır. Topoloji optimizasyonu uygulanarak sonuç alınmıştır.
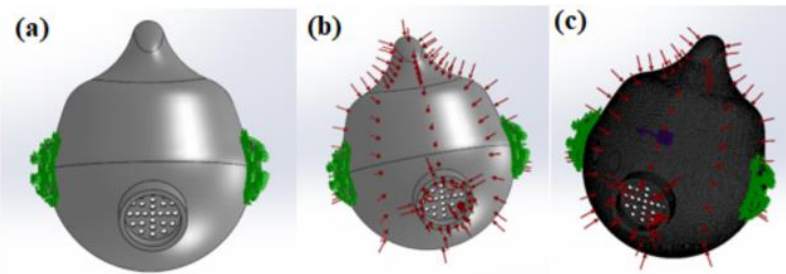

Şekil 4. N95 maskenin topoloji optimizasyon ön işlemleri a) sabitlemeler b) yük uygulanması c) mesh görüntüsü

\subsubsection{N95 maske imalatı}

N95 maskenin imalatı 3B yazıcı kullanarak yapılmıştır. Tablo 3'de görüldüğü gibi Cura 3B programı ile işleme parametreleri oluşturulmuş ve tasarlanan katı modeller imal edilmiştir.
Tablo 3. 3B yazıcı imalat parametreleri

\begin{tabular}{|c|c|c|c|c|}
\hline & \multicolumn{4}{|c|}{ Hafifletme } \\
\cline { 2 - 5 } & Yok & $\mathbf{\% 3 0}$ & $\mathbf{\% 4 0}$ & $\mathbf{\% 5 0}$ \\
\hline Basma Hızı (mm/sn) & 50 & 50 & 50 & 50 \\
\hline Katman Kalınlığı (mm) & 0.2 & 0.2 & 0.2 & 0.2 \\
\hline Doluluk Oranı $(\%)$ & 15 & 15 & 15 & 15 \\
\hline Tabla Sıcaklığı $\left({ }^{\circ} \mathrm{C}\right)$ & 50 & 50 & 50 & 50 \\
\hline Nozzle Sicaklığı $\left({ }^{\circ} \mathrm{C}\right)$ & 210 & 210 & 210 & 210 \\
\hline İmalat Süresi $(\mathrm{dk})$ & $\cong 450$ & $\cong 360$ & $\cong 330$ & $\cong 300$ \\
\hline
\end{tabular}

Şekil 5a'da gösterildiği gibi tam dolu N95 maske için imalat tamamlandıktan sonra destek parçaları ile birlikte imalat görüntüsü verilmiştir. Şekil 5b'de $\% 30$ hafifletme oranı ile topoloji optimizasyonu uygulanmış N95 maske imalatı tamamlanmış son işlem olarak parçanın üzerindeki baskıda oluşan destek parçaları zımpara yardımı ile temizlenip, maske kullanıma hazır hale getirilmiştir. Şekil 5c ve Şekil 5d'de $\% 40$ ve $\% 50$ hafifletme oranı ile topoloji optimizasyonu uygulanmış N95 maske başarılı biçimde imalatı gerçekleştirilmiştir. Daha sonra gerekli son işlemler yapılarak maske kullanıma hazır hale getirilmiştir.
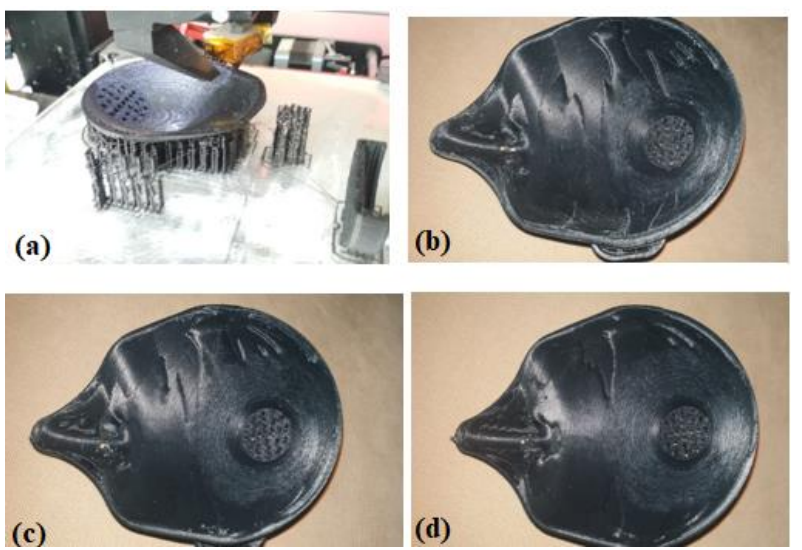

Şekil 5. 3B yazıcı imalat sonrası N95 maske görüntüleri a) tam dolu b) $\% 30$ hafifletme, c) $\% 40$ hafifletme, d) $\% 50$ hafifletme

\section{BULGULAR}

Çalı̧̧mada, N95 maskenin Solidworks programı ile tasarlanmış ve 3B yazıcı ile imalatı gerçekleştirilmiştir. Tasarımlar \%30, \%40, \%50 ve tam dolu modeller olmak üzere 4 model olarak tasarımı gerçekleştirilmiştir. Daha sonra Solidworks Simülasyon ${ }^{\circledR}$ programı ile yapılan topoloji optimizasyonu sonuçlarına göre aşağıda verilen grafikler elde edilmiştir. Şekil 6'da $\% 30$ hafifletme oranında N95 maskenin topoloji optimizasyon sonuçları verilmiştir. Şekil 6a'da malzeme kütle görüntüsüne göre $0,0461 \mathrm{~kg}$ ağılık elde edilmiştir. Ayrıca hafifletme malzemesi kaldırılabilir bölgeler açık mavi renk ile gösterilmiştir. Sarı bölgeler mutlaka N95 parça üzerinde kalmalıdır. Şekil 6b'de Von-mises gerilmesi görüntüsü verilmiştir. Çalışmada en büyük Von-Mises gerilimi 149,6 MPa elde edilirken, en küçük Von-Mises gerilimi $12,5 \mathrm{MPa}$ elde edilmiştir. Şekil $6 c^{\prime}$ 'de gösterildiği gibi yer değiştirme miktarı en büyük 1,24 mm elde edilirken, en küçük 0,1033 mm elde edilmiştir. Yer değiştirme miktarının en fazla olduğu bölge maskenin burun kısmında bulunmaktadır. Şekil 6d'de topoloji statik gerinim görüntüsü verilmiştir. En büyük değişken gerinimi $0,038 \mathrm{MPa}$ elde edilirken, en küçük değişken gerinimi $0,0031 \mathrm{MPa}$ olarak elde edilmiştir. 


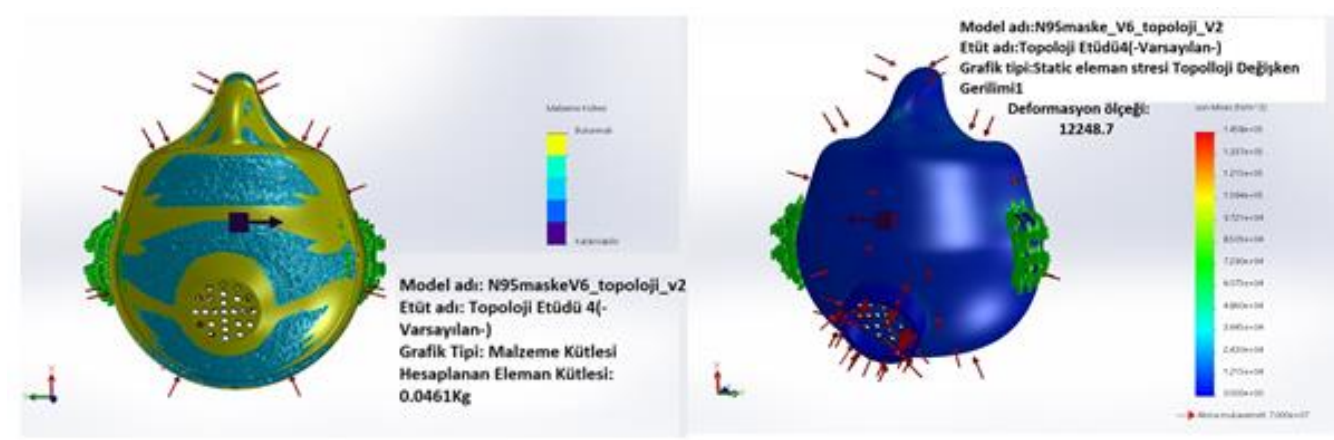

(a)

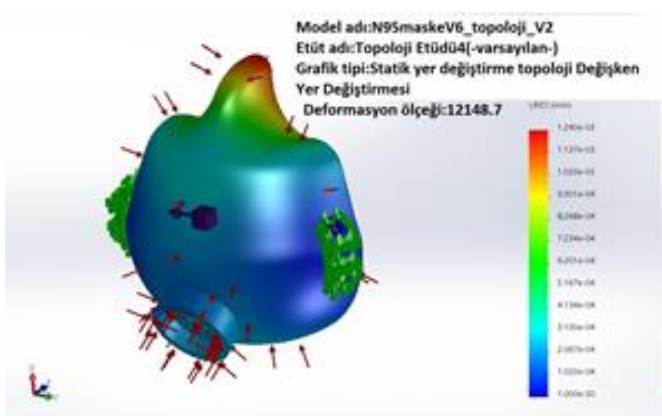

(c)

(b)



(d)

Şekil 6. N95 maskenin \%30 oranında hafifletme topoloji optimizasyon sonuçları (a) malzeme kütlesi, (b) Von-Mises gerilmesi, (c) statik yer değiştirme, (d) statik gerinim

Şekil 7'de \%40 hafifletme oranında N95 maskenin topoloji optimizasyon sonuçları verilmiştir. Şekil 7a'da malzeme kütle görüntüsüne göre 0,03961 kg ağırlık elde edilmiştir. Şekil 7b'de Von mises gerilmesi görüntüsü verilmiştir. Çalışmada en büyük Von-Mises gerilimi 145,8 MPa elde edilirken, en küçük VonMises gerilimi 12,1 MPa elde edilmiştir. Şekil 7c'de gösterildiği gibi yer değiştirme miktarı en büyük 1,22 mm elde edilirken, en küçük $0,1017 \mathrm{~mm}$ elde

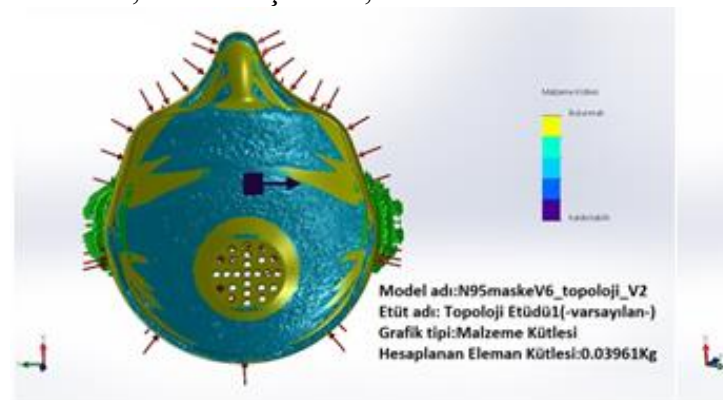

(a)

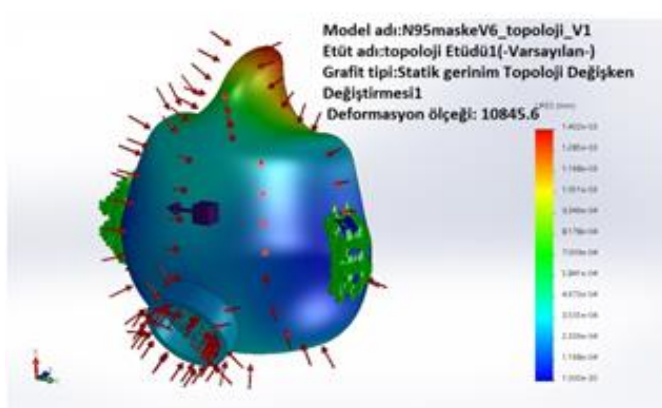

(b) edilmiştir. Yer değiştirme miktarının en fazla olduğu bölge maskenin burun kısmında bulunmaktadır. Şekil 7d'de topoloji değişken gerinim görüntüsü verilmiştir. En büyük değişken gerinimi 0,030 MPa elde edilirken, en küçük değişken gerinimi $0,0025 \mathrm{MPa}$ olarak elde edilmiştir.

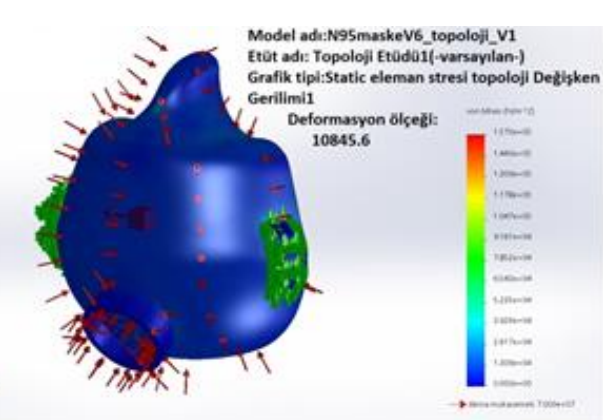

(b)

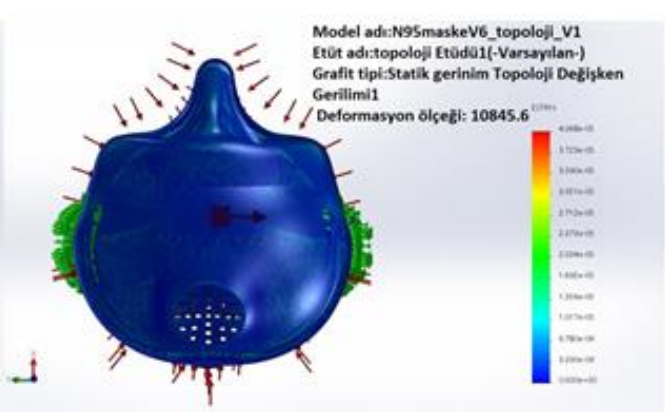

(d)

Şekil 7. N95 maskenin $\% 40$ oranında hafifletme topoloji optimizasyon sonuçları (a) malzeme kütlesi, (b) Von-Mises gerilmesi, (c) statik yer değiştirme, (d) statik gerinim 
Şekil 8'de \%50 hafifletme oranında N95 maskenin topoloji optimizasyon sonuçları verilmiştir. Şekil 8a'da malzeme kütle görüntüsüne göre $0,033125 \mathrm{~kg}$ ağırlık elde edilmiştir. Şekil 8b'de Von-Mises gerilmesi görüntüsü verilmiştir. Burada en büyük Von-Mises gerilimi 0,84 MPa elde edilirken, en küçük Von-Mises gerilimi $0,07 \mathrm{MPa}$ elde edilmiştir. Şekil 8c'de gösterildiği gibi yer değiştirme miktarı en büyük 0,0083

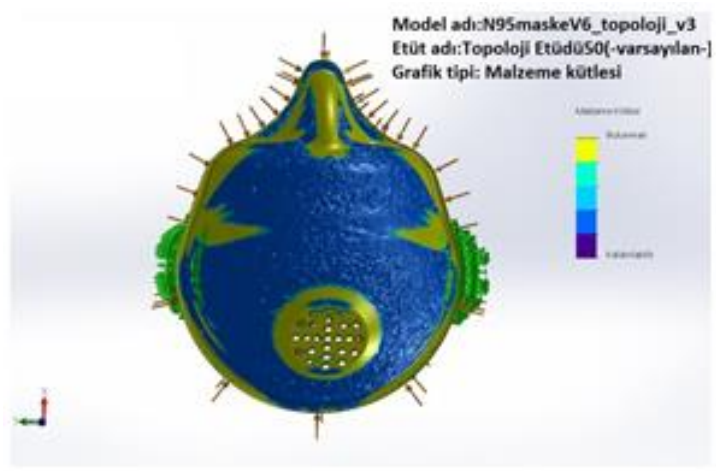

(a)

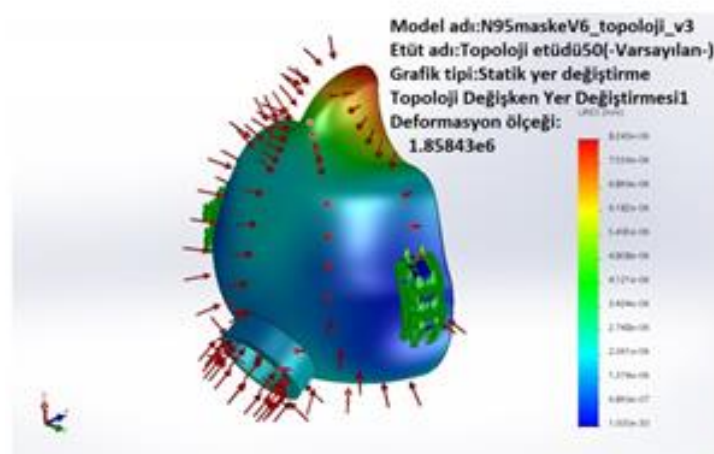

(c) mm elde edilirken, en küçük 0,00069 mm elde edilmiştir. Yer değiștirme miktarının en fazla olduğu bölge maskenin burun kısmında bulunmaktadır. Şekil 8d'de topoloji değişken gerinim görüntüsü verilmiştir. En büyük değişken gerinimi $0,00037 \mathrm{MPa}$ elde edilirken, en küçük değişken gerinimi $0,00003 \mathrm{MPa}$ olarak elde edilmiştir.

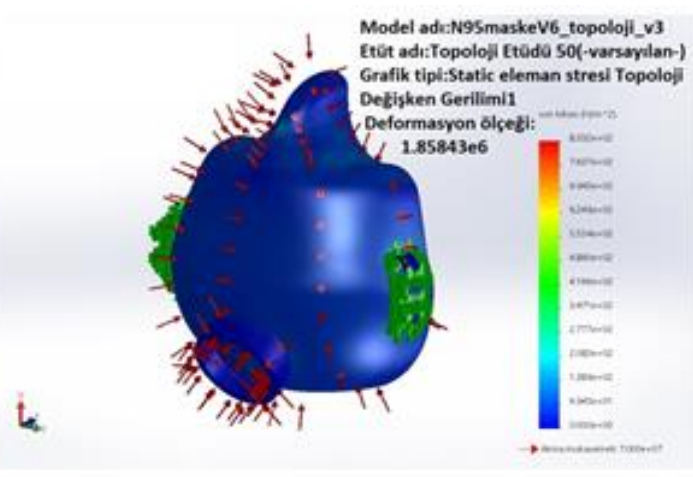

(b)

Şekil 8. N95 maskenin \%50 oranında hafifletme topoloji optimizasyon sonuçları (a) malzeme kütlesi, (b) Von-Mises gerilmesi, (c) statik yer değiștirme, (d) statik gerinim

Şekil 9'de N95 maskenin topoloji optimizasyon uygulanmamış halinin görüntüsü verilmiştir. Şekil 9a'da gösterildiği gibi N95 maskenin hesaplanan orijinal kütlesi 0,066279 kg'dır. Şekil 9b'de Von-Mises gerilmesi görüntüsü verilmiștir. Burada en büyük VonMises gerilimi $157 \mathrm{MPa}$ elde edilirken, en küçük VonMises gerilimi 13,1 MPa elde edilmiştir. Şekil 9c'de gösterildiği gibi yer değiştirme miktarı en büyük 1,40 mm elde edilirken, en küçük $0,12 \mathrm{~mm}$ elde edilmiştir. Yer değiștirme miktarının en fazla olduğu bölge maskenin burun kısmında bulunmaktadır. Şekil 9d'de topoloji değişken gerinim görüntüsü verilmiştir. En büyük değişken gerinimi $0,041 \mathrm{MPa}$ elde edilirken, en küçük değişken gerinimi $0,0034 \mathrm{MPa}$ olarak elde edilmiştir. 3B yazıcı imalat sonrası N95 maske ağırlık ölçümleri yapılmıştır. Daha sonra N95 maskenin topoloji optimizasyon simülasyon sonuçları ile N95 maskelerin ağırlık değerleri karşılaştırmalı olarak Tablo 4'de verilmiştir.

Tablo 4. Topoloji optimizasyon ile N95 maskelerin karşılaştırmalı ağırlık ölçümlerin gösterimi

\begin{tabular}{|c|c|c|c|c|}
\hline & \multicolumn{4}{|c|}{ Hafifletme } \\
\cline { 2 - 5 } & Yok & $\mathbf{\% 3 0}$ & $\mathbf{\% 4 0}$ & $\mathbf{\% 5 0}$ \\
\hline $\begin{array}{c}\text { Simülasyonda } \\
\text { hesaplanan ağırlığı (gr) }\end{array}$ & 66,27 & 46,10 & 39,61 & 33,12 \\
\hline $\begin{array}{c}\text { İmal edilen parçanın } \\
\text { ağırlığı (gr) }\end{array}$ & 66,60 & 46,33 & 39,81 & 33,29 \\
\hline
\end{tabular}




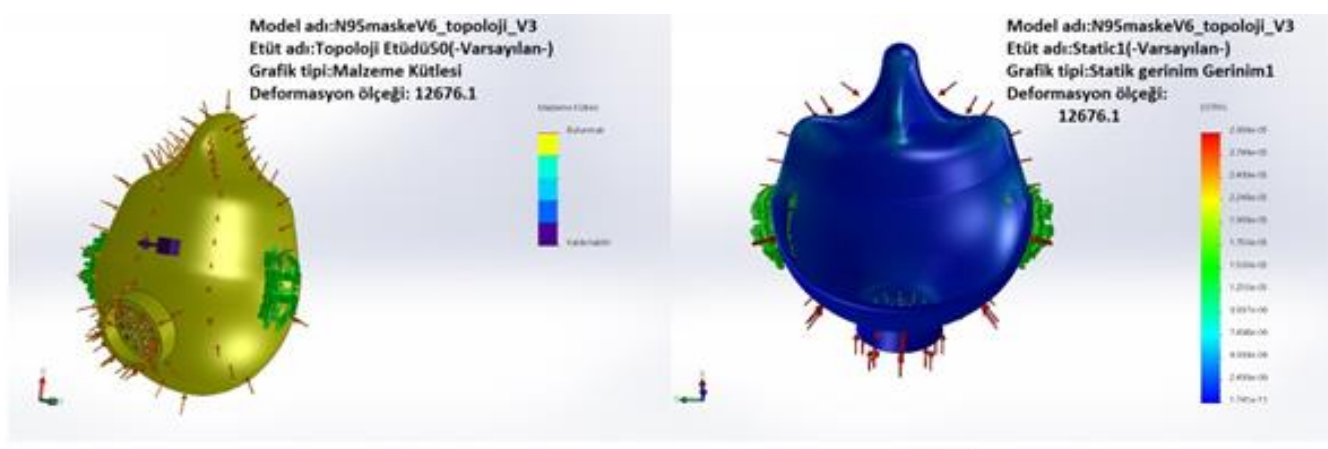

(a)

(b)

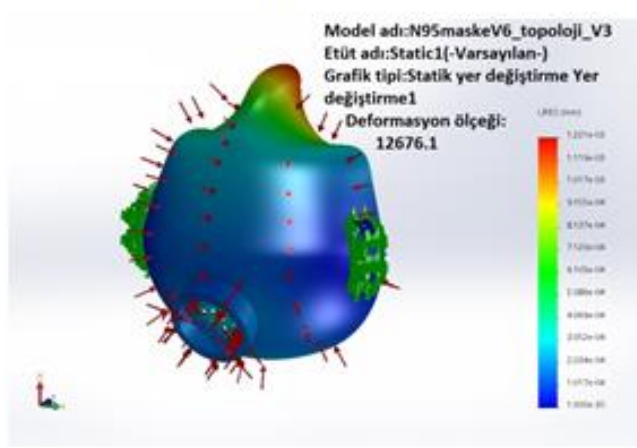

(c)

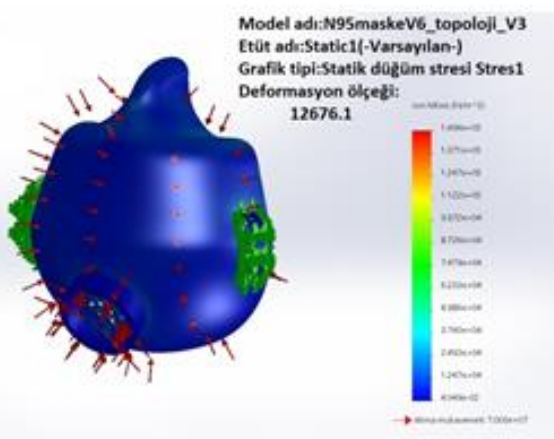

(d)

Şekil 9. N95 maskenin orijinal kütlesinde topoloji optimizasyon sonuçları (a) malzeme kütlesi, (b) Von-Mises gerilmesi, (c) statik yer değiştirme, (d) statik gerinim

\section{SONUÇLAR}

Çalışmada, N95 maske tasarımı üzerine topoloji optimizasyonu Solidoworks ${ }^{\circledR}$ simülasyon programı ile gerçekleştirilmiştir. Ayrıca 3B baskı cihazı ile üretilip ağırlıkları ölçülmüştür. Elde edilen sonuçlar karşılaştırmalı olarak değerlendirilmiştir ve aşağıdaki genel sonuçlar elde edilmiştir:

- N95 maske $\% 30, \% 40$ ve $\% 50$ hafifletme oranında topoloji optimizasyon başarılı biçimde uygulanmıştır.

- Topoloji optimizasyonu uygulanmış N95 maske ağırlıkları, simülasyonda hesaplanan ağırlıklara göre tam dolu katı model sapma miktarı \%0,49 oranıdır. Yüzdelik hafifletme oranına göre sapma miktarları $\% 30$ oranında $0,49, \% 40$ oranında $\% 0,50, \% 50$ oranında \%0,51'dir. Ayrica artan hafifletme oranına bağlı olarak hem imal edilen hem de simülasyonda hesaplanan ağırlık miktarları da azalma meydana gelmiştir.

- N95 maske için tam dolu modele en yakın VonMises gerilimi, gerinim ve yer değiştirme \%30 hafifletme oranında gerçekleştirilmiştir. Artan hafifletme oranı Von-Mises gerilimi, gerinimi ve yer değiştirme değerlerini düşürmüştür.

- Elde edilen sonuçlara göre tam dolu katı modele en yakın sonuçları veren model \%30 hafifletme yapılan model olmuştur. Hem parçanın mekanik özellikleri büyük oranda korunmuş hem de yaklaşık $\% 20$ oranında malzemeden tasarruf edilmiştir. $\mathrm{Bu}$ sonuçlara göre N95 maske için \%30 orandaki hafifletme topoloji optimizasyonu en uygun tercih olduğu görülmüştür.

\section{KAYNAKLAR}

[1] Tekin A. Sağlık-Hastalık Olgusu Ve Toplumsal Kökenleri [yüksek lisans tezi]. Isparta: Süleyman Demirel Üniversitesi Sosyal Bilimler Enstitüsü Sosyoloji Anabilim Dalı; 2007.

[2] Krauss, H. Weber A., Appel, M. , Enders B., Graevenitz A. v., Isenberg H. D., Schiefer H. G., Slenczka W., Zahner H. Infectious Diseases Transmissible from Animals to Humans. 3rd Edition, 456 pages. ASM Press. American Society for Microbiology, Washington DC., USA. 2003.

[3] Til, U. D. A., Yeni Koronavirüs hastalığ Hakkında bilinmesi gerekenler. Ayrıntı Dergisi, 2020; 8(85), 53-57.

[4] Wikipedia [Internet]. 2020 [cited 2020 Jun 17]. Available from: https://tr.m.wikipedia.org/wiki/COVID-19

[5] Çetintepe, S. P., İlhan, M. N., COVID-19 Salgınında Sağlık Çalışanlarında Risk Azaltılmas1. Journal of Biotechnology and Strategic Health Research,2020; 4, 50-54.

[6] He, H., Gao, M., Illés, B. Molnar, K. 3D Printed And Electrospun, Transparent, Hierarchical Polylactic Acid Mask Nanoporous Filter. International Journal Bioprint. 2020; 6(4).

[7] Iyengar, K., Bahl, S., Raju, V. Vaish, A. Challenges and Solutions İn Meeting Up The Urgent Requirement Of Ventilators For Cov1d-19 Patients. Diabetes Metabolic Syndrome: Clinical Research \& Reviews 2020; 14, 499-501.

[8] Şahan, C., Özgür, E. A., Arkan, G., Alagüney, M. E., Demiral, Y. COVID-19 Pandemisi'nde Meslek Hastalığı Tanı Kılavuzu,2020. 
[9] Mahouti, P. 3 Boyutlu Yazıcı Teknolojisi İle Bir Mikroşerit Yama Antenin Maliyet Etkin Üretimi, Mühendislik Bilimleri ve Tasarım Dergisi, 2019, 7(3), 473-479.

[10] Choong, Y. Y. C., Tan, H. W., Patel, D. C., Choong, W. T. N., Chen, C. H., Low, H. Y., Chua, C. K. The Global Rise Of 3D Printing During The Covid-19 Pandemic. Nature Reviews Materials, 2020; 5(9), 637-639.

[11] Duman, B., Kayacan, M. C, Seçmeli lazer sinterleme tezgâhı için imalat yazılımı geliştirilmesi. Uluslararası Teknolojik Bilimler Dergisi, 2016; 8(3), 27-45.

[12] Ertugrul, I. The Fabrication of Micro Beam from Photopolymer by Digital Light Processing 3D Printing Technology. Micromachines, 2020, 11.5: 518.

[13] Çelebi, A., Seziş, Ü. G. Katmanlı imalatta destek yapısının ve konumlandırmanın çarpılma üzerine etkisinin simufact additıve yazılımı ile simülasyonu. International Journal of 3D Printing Technologies and Digital Industry, 2019; 3(2), 182-188.

[14] Ishack, S., \& Lipner, S. R. (2020). Applications of 3D Printing Technology to Address COVID-19 Related Supply Shortages. The American Journal of Medicine.

[15] Li, J., Tanaka, H., \& Miyagawa, S. (2018, July). Applying the Programmable Modeling Tool to Support the Hospital Infection Control Staff in Customizing the Filtering Face-Piece Respirators for Health Care Worker. In International Conference on Applied Human Factors and Ergonomics (pp. 270-279). Springer, Cham.

[16] R. J. Morrison, K. N. Kashlan, C. L. Flanangan, J. K. Wright, G. E. Green, S. J. Hollister, K. J. Weatherwax, Clinical and translational science, $2015 ; 8,594$.

[17] M. Di Prima, J. Coburn, D. Hwang, J. Kelly, A. Khairuzzaman, L. Ricles, 3D printing in medicine, 2016; $2,1$.

[18] Davies, A., Thompson, K. A., Giri, K., Kafatos, G., Walker, J., Bennett, A. Testing the efficacy of homemade masks: would they protect in an influenza pandemic?. Disaster medicine and public health preparedness, 2013; 7(4), 413-418.

[19] Provenzano, D., Rao, Y. J., Mitic, K., Obaid, S. N., Pierce, D., Huckenpahler, J., Loew, M. H. Rapid Prototyping of Reusable 3D-Printed N95 Equivalent Respirators at the George Washington University, 2020. 